\title{
11. Agar-gel-electrophoresis and Immunoelectrophoresis of Cerebrospinal Fluid Proteins
}

\author{
Kuniyuki Someda and Naoki KageYama \\ 1st Surgical Division, Kyoto University.
}

Cerebrospinal fluid proteins from patients with neurological diseases, especially from neurosurgical cases and from healthy persons were analysed electrophoretically and immunoelectrophoretically.

Pherograms of CSF proteins from neurologically normal persons were characterized by a presence of prealbumin and $\tau$-fraction and by a low and flat $\gamma^{-}$ globulin fraction. Immunoelectrophoretically, there were $\rho_{2}, \alpha_{1}{ }^{-}$and $\alpha_{2}$-lipoproteins normally. $\beta_{1}$-lipoprotein was, however, never recognized in CSF from normal persons.

Pherograms of CSF proteins from patients with intracranial tumors were found frequently to be more or less similar to those of serum proteins. $\beta_{1}$-lipoprotein was commonly identified in these tumor cases by immunoelectrophoresis. In almost all cases that showed extremely serum-like pherogram, it was found that precipitation line pattern of lipoproteins was quite similar to that of serum (i.e. thick precipitation lines of $\alpha_{1}$ - and $\beta_{1}$-lipoprotein and scarcely recognizable $\alpha_{2}-\mathrm{L}$ and $\rho_{2}$ precipitation lines) and that a precipitation line of $\alpha_{2}$-macroglobulin was of distinct type as in serum, the arc of transferrin-II was not found and a precipitation line of $\beta_{2}$-macroglobulin was recognized. These changes both in pherogram and in precipitation line pattern can be explained by an abnormal entrance of serum proteins into the CSF.

No distinct change was found in CSF proteins from patients with epilepsy, sequealae after head injury, extrapyramidal diseases and others.

Hitherto unknown fraction in CSF was demonstrated in the $\beta_{2}$-region with rabbit's antiserum for human-cerebrum absorbed with human serum. It is considered to be of an origin in the central nervous system.

12. Studies on the Intensible Water Loss in the Neurosurgical Patients

\author{
Yasuhiro HiraYama, Shigeru Nomura and Masatoshi Morooka \\ 2nd Dept. of Surgery, Juntendo University School of Medicine
}

The first report on this problem was made at 21 st. Japanese neurosurgical society. 